\title{
Canadian Transport Medicine: Waypoints and Destinations
}

\author{
D. Gregory Powell, MD, OC*; Andrew L. McCallum, MD*
}

\section{INTRODUCTION}

Canada, the second largest country by area in the world, is mainly situated above the 49th parallel. Its terrain is vast and rugged. The weather can be extreme, ranging from -60 to $+40^{\circ} \mathrm{C}$. Although the vast majority of the population is within $100 \mathrm{~km}$ of the border near the most specialized health care, providing care to the people in the Northern and rural areas of the country is an essential duty of the Canadian health care system. This duty is met through various strategies, most notably by transport medicine. What follows is a brief introduction to this evolving modality with some predictions for the future.

\section{HISTORY}

Patient transport started with land transportation, which evolved to dedicated land ambulances. The availability, crew capability, and technology of land ambulances improved, often in tandem with air operations.

As aviation technology advanced in Canada and elsewhere, the long distances for patient transport and care led to aircraft functioning as ambulances. Northern based bush planes have been used as air ambulances since the early 1900s. At the outset, aircraft were necessarily multipurposed. Thus, air ambulances became a mixture of the commandeering of space on scheduled flights to the use of bush planes to an ever-expanding use and integration of helicopters. Initially, provincial programs focussed on using available centrally located or peripherally based charter aircraft on a case by case basis. Advances in demand and capability led to dedicated aircraft functioning as ambulances.

Most often, centrally or remotely based multi-purpose charter companies operated air ambulances, charging hourly rates to transport patients. In the parts of the country where feasible, military aircraft that had search and rescue capability often served as air ambulances, including larger transport aircraft such as the Lockheed C-130 Hercules.

In 1946, the Saskatchewan government launched Saskatchewan Air Ambulance, which was thought to be the first government sponsored dedicated program, perhaps in the world. Since that time, provincial programs have used fixed wing $(\mathrm{FW})$ aircraft, with rotary wing (RW) aircraft (helicopters) only coming into wide civilian use in the 1970s, after demonstrating their utility in war. Indeed, global conflict has driven much innovation in FW and RW aviation. Across Canada, there are now programs serving every province and territory with a variety of governance, financial, and staffing configurations.

RW aircraft as part of the EMS were introduced in Canada in the 70s and 80s. STARS was founded by one of the authors (D.G.P.) in response to a need for rapid retrieval and transport of critically ill patients in Alberta and eastern British Columbia, later expanding to serve Saskatchewan and Manitoba. Bandage 1 in Ontario was the first of a series of RW aircraft introduced throughout Ontario to meet a similar need. British Columbia and Nova Scotia developed RW programs in the period thereafter.

It should also be noted that there are some air ambulance operators based in smaller centers, both fixed wing and rotary across Canada. There are also multiple pre-

From the *University of Calgary, Calgary AB (DGP) Queens University, Kingston ON (AMCC).

Correspondence to: Dr. Andrew L. McCallum, c/o Ornge, 5310 Explorer Dr., Mississauga ON L4W5H8; Email: andrewlemaymccallum@gmail.com which permits unrestricted re-use, distribution, and reproduction in any medium, provided the original work is properly cited. 
approved charter operators providing air ambulance, notably serving northern and the more remote areas of Canada.

\section{ROTARY AND FIXED WING EVOLUTION}

The first medical use of aircraft was simple patient transport. Aircraft were relatively slow and unreliable, with limited all-weather capability. Few early aircraft had pressurization or climate control. Little care could be delivered to the patient en route. No monitoring of vital signs was possible in the noisy, confined, and uncomfortable cabin. Often, a nurse or physician was required to accompany the patient depriving their community of scarce health care resources.

After WW II, aircraft technology advanced rapidly, obviating many of the foregoing concerns. Pressurized turboprop aircraft were fast, had all-weather capability with comfortable cabins and excellent load carrying capability.

The personnel and care issues were dealt with in varying ways across Canada. By the turn of the 20th century, a nurse-paramedic (CCP-RN) configuration was common, while Ontario and British Columbia have employed paramedic-paramedic (CCP-CCP/ACP) crews. In all cases, the leading systems have evolved critical care capability, including advanced airway management, standing orders, and medical directives that allow nearICU interventions and the ability to "patch" with or have on-board an emergency physician and/or intensivist with pediatric and adult care capability.

RW aircraft are used in the most densely populated areas of Canada, taking advantage of their flexible landing capability to land close to the patient and transport them to a hospital landing pad. For trauma patients, helicopters are an essential means to rapidly take the patient to the most appropriate hospital. Generally, crewing of Canadian ambulance helicopters is equivalent to fixed wing.

\section{DEVELOPMENT OF THE CANADIAN TRANSPORT MEDICINE ASSOCIATION}

Air medical programs across Canada send representatives to conferences around the world-Association of Air Medical Services (AAMS), AST (Aeromedical Society of Australasia), and AirMed to name a few. Often at these international conferences, the Canadian attendees would gather separately for relatively short meetings to share Canadian information.
Although organizations/governments across the globe share the goal of providing rapid, efficient care to the critically ill and injured, with the mantra of delivering the right care to the appropriate patient in the right amount of time, there are many differences in the scope of medical practice, geographical challenges, funding, and governance structure.

As STARS began providing services across parts of the four western provinces, many of those same issues were encountered within our own country and local jurisdictions. Programs in Canada varied in governance models, funding availability, type of aircraft, geographical response, safety requirements, clinical levels of training, and credentials of healthcare providers to name a few.

As accrediting organizations such as the Commission on Accreditation of Medical Transport Systems (CAMTS) provided standards, STARS leadership felt the need to develop both patient care and aviation standards directly relevant to Canada. It was also important to share learnings and challenges with comparable organizations. Differences, similarities, and research initiatives could all be productively addressed in a collective environment rather than in isolation.

In consultation with Canadian air medical program leaders, the STARS leadership spearheaded an invitation to a small number of leaders in aeromedical transport to Calgary from across Canada. The format, content, and length of a meeting was discussed. It was believed that a limited number of attendees focussed on the most difficult clinical issues in critical care transport would be an appropriate initial meeting and starting point.

The opportunity to share clinical approaches to problems, meeting standards, research initiatives, and visions of the future made up this initial agenda.

There was no deliberate forecast of ongoing activity after that meeting. However, attendees embraced the concept, and since that first meeting in 2016, subsequent conferences have occurred in Toronto (ORNGE), Halifax (NS Lifeflight), and Vancouver (BCEHS). The next meeting is planned for Winnipeg (STARS) in 2020.

Attendance has grown, diverse health care providers have attended, and an approach to an organized Canadian aeromedical network and structure has evolved.

\section{THE FUTURE}

The Canadian medical transport system is uniquely positioned to innovate. It is not profit driven and, thus, is free to explore any option that will provide better cost- 
effective patient outcomes. Particularly, not all patients who come to the attention of Canadian air ambulance systems must be transported. Other options such as care in place or triage to a different mode of transport can be chosen without adversely affecting the operator's economic viability. Thus, innovation can occur in two spheres, the care of the patient while in motion and care of the patient in situ.

In the sphere of care interventions, there is much innovation. Interventions such as ECMO (extracorporeal membrane oxygenation) and blood product administration are now adopted and further leadingedge interventions will follow. POCUS (point of care ultrasound) and spectroscopic detection of intracranial bleeding are on the horizon. Drones may play a role in delivery of life-saving medicines or treatments, aided by automation.

Innovations in the other sphere are also numerous. Modalities such as the ELC (Emergency Link Centre) system at STARS, which monitors and provides remote site health care, and real-time telemedicine at triage in the Ornge Operations Control Centre are but two of these. Air ambulance systems may also play a role in health maintenance and prevention of disease by projecting screening and interventions into remote settings, in a manner analogous to community paramedicine in urban centers. Technologies that allow minimally trained personnel to screen for disease complications, such as retinopathy, can potentially be used by means of air ambulance, for example.

The recent pandemic of COVID-19 (coronavirus disease 2019) has demonstrated the central role that medical transport plays in integrating the response to unforeseen events. Medical transport providers play a central role in the response to such events and will continue to do so in the future. It is essential that transport needs be planned for and contingencies be imagined/anticipated to avoid unnecessary adverse outcomes.

The advent of the Canadian Medical Transport Association provides a forum for the exchange of ideas and the consideration of opportunities to collaborate. It creates a crucible in which ideas can be debated and tested, and if found promising, planned and implemented.

Finally, it is clear that the needs of patients in remote and/or northern communities must continue to be met. The foundation provided by the CTMA will ensure that this happens in an innovative and collaborative environment. The Canadian health care environment, although challenged, is a fertile place for ideas and collaboration in the field of transport medicine. Indeed, it is possible that this will produce a larger field, inclusive of transport medicine, which might be termed "distance medicine." 